\title{
SIGUI MINUSCULISTA, NO POSI COMES QUAN RESPIRI I ALTRES PETITS CONSELLS PER REDACTAR TEXTOS A LES EMPRESES
}

\author{
Alberto Gómez Font \\ Fundación del Español Urgente (Fundéu BBVA)
}

Un dels millors consells ortogràfics que m'han donat mai és el següent: «Davant del dubte: minúscula». I el millor de tot va ser l'explicació: «Si, en començar a escriure una paraula, et sorgeix el dubte entre escriure-la amb majúscula o amb minúscula inicial, el millor serà optar per la minúscula, ja que així és molt probable que encertis, perquè hi ha un $95 \%$ de probabilitats al teu favor». També recordo amb afecte una frase que li vaig sentir pronunciar al lingüista Fernando Lázaro Carreter: «El minusculisme és més higiènic que el majusculisme».

I així ho faig: quan dubto, poso minúscula; però de vegades el dubte persisteix, perquè hi ha tants casos especials en aquest terreny que poden donar-se situacions en les quals hi hagi punts de vista diferents. Precisament per això acaba de publicar-se un llibre dedicat completament a aclarir aquest tema en castellà: el Diccionario de uso de las mayúsculas y minúsculas, de José Martínez de Sousa.

Aquests dubtes són també els causants que en tots els manuals o llibres d'estil -la majoria de mitjans de comunicació- es dediqui un capítol més o menys extens a explicar l'ús de les majúscules, capítol que també hauria d'ocupar un espai important en el de les normes de redacció de les empreses.

És habitual que - sobretot en els documents jurídics de les empresesapareguin majúscules per tot arreu, moltes, per tots els racons, fins al punt que un pot imaginar-se que a sobre de les taules dels qui redacten aquests escrits hi ha una capseta amb majúscules, al costat de la dels clips, d'on les prenen per adornar els texts com si fossin les boles de colors dels arbres de Nadal.

I n'hi ha algunes que s'incrusten i són força difícils d'eradicar: en castellà apareixen escrites amb majúscula inicial les paraules que denominen càrrecs relacionats amb l'advocacia: Notario, Procurador, Juez, Magistrado, etc.; també les relacionades amb l'Administració: Director General, Subsecretario, Ministro, Gobernador, Presidente, etc., i encara les que tenen a veure amb la legislació: Ley, Orden, Estatuto, Reglamento, etc.

Però hi ha una cosa que ha de quedar clara: en castellà només s'escriuen amb majúscula els noms propis, i cap de les paraules abans esmentades ho són, sinó que són noms comuns, com príncipe, rey i papa.

No és un tema menor, ja que la pulcritud dels documents depèn sobretot de la bona ortografia.

Però aquest no és l'únic problema gràfic dels textos que es redacten en el món empresarial; n'hi ha un altre, tan cridaner o més que l'anterior, que és l'ús a tort i a dret de les comes. Es posen comes per tot arreu, com si a més de la capseta de les majúscules hi hagués també a sobre de les taules de tots els despatxos una altra capseta amb comes, que els qui redacten els documents agafen amb els dits índex i polze i deixen caure, com si es tractés de sal o pebre, sobre els fulls escrits, per després treure únicament les que hagin caigut en els marges...

Algun dia algú va tenir la idea esperpèntica de dir que calia posar una coma cada vegada que, en llegir un text en veu alta, es fes una pausa per respirar, i l'inconvenient d'això és que aquesta persona va tenir molt d'èxit $i$ va convèncer milers $\mathrm{i}$ milions de parlants per mitjà, suposo, d'una campanya sofisticada de màrqueting, fins al punt que avui dia hi ha molta gent convençuda que és correcte posar comes amb cada moviment d'inspiració d'aire.

I què es pot dir de les cometes...? I de les cursives? Però recapitulem: tot això va començar a ocórrer en els documents de les 
empreses, de totes les empreses i també dels organismes de l'Administració — no se salva ningú- aquell fatídic dia que els que ja teníem els cabells blancs vam sofrir el trauma (des de llavors molts estem en mans del psicoanalista) de la desaparició de les nostres vides de la màquina d'escriure, aparell amb el qual tantes penes i alegries havíem compartit, i l'arribada als despatxos d'un artefacte electrònic amb pantalla de televisió que es va anomenar ordinador (pres del francès ordinateur), mentre la resta dels nostres germans de llengua l'anomenaven computadora o computador. I amb ell van arribar els programes d'edició de textos en els quals ja no solament hi havia minúscules, majúscules i subratllat, com en les màquines d'escriure, sinó que també hi havia un munt de signes i tipus de lletres; però a ningú no se li va ocórrer que els usuaris d'aquests programes necessitaríem un curs d'introducció a l'ortotipografia: quan cal usar el guionet? quan el guió llarg? per a què són les negretes? i la cursiva?

Amb aquesta nova joguina entre mans molts es van llançar a la piscina $i$ es van dedicar a barrejar el que no es pot barrejar, com les cometes i la cursiva, a causa del desconeixement de l'ús correcte d'ambdós recursos. Així, és habitual trobar textos impresos en els quals hi ha paràgrafs tancats entre cometes i amb lletra cursiva, la qual cosa és redundant, ja que, si el que es pretén és mostrar que es tracta d'una citació textual, n'hi ha prou amb les cometes. I si, per raons estètiques, es prefereix usar la lletra cursiva, les cometes no són necessàries, ja que n'hi ha prou amb la informació que se'ns dóna en canviar el tipus de lletra.

De totes maneres, per marcar que es tracta d'una citació és millor no usar mai la cursiva i usar altres recursos (si no es volen emprar les cometes), com estrènyer la caixa del text $\mathrm{i}$ ampliar els marges o compondre'l amb un cos de lletra més petit.

També anomenada itälica, la cursiva s'utilitza quan es vol destacar alguna paraula o frase dintre del text (és la mateixa funció que tenia el subratllat en les antigues màquines d'escriure).
És molt estrany, estranyíssim, que en una empresa hi hagi algú que conegui bé l'ortotipografia (ni tan sols l'ortografia), motiu pel qual s'ensopega constantment amb els problemes fins aquí comentats; però no acaben aquí... n’hi ha més, alguns més, i un d'ells és el desconeixement dels canvis ortogràfics en el castellà —d'accentuació gràfica - adoptats per l'Asociación de Academias de la Lengua Española i publicats en l'Ortografía de la Lengua Española, de la Reial Acadèmia Espanyola, el 1959 i el 1999. Comencem pels primers, pels més vells, els quals no hi ha cap excusa per no aplicar-los i molt menys per desconèixer-los.

En els congressos de l'Asociación de Academias de la Lengua Española s'aproven algunes decisions que, pel que fa a l'ortografia, solen tendir a la simplificació, és a dir, a fer les coses més fàcils als usuaris del castellà.

Dos d'aquests canvis, relacionats amb l'accentuació en castellà, es van aprovar en el II Congrés d'Acadèmies de la Llengua Espanyola, dut a terme el 1956, on es va tractar sobre la paraula solo i els pronoms demostratius, que a partir d'aquest moment han d'accentuar-se només en cas d'ambigüitat, o el que és el mateix, quan hi hagi el perill d'entendre el text amb dos significats diferents.

En les tres últimes edicions de l'Ortografía de la Lengua Española, de la Reial Acadèmia Espanyola (1959, 1974 i 1999), s'indica que la paraula castellana solo no s'accentua, excepte quan signifiqui 'solament' i, si no s'accentua, pot haver-hi risc d'ambigüitat, és a dir, que la frase tingui dues lectures. Però aquest risc d'ambigüitat només és possible en frases aillades, fora de context. Així, doncs, en els textos de les empreses no cal accentuar mai en castellà la paraula solo.

Els demostratius (ese, esa, esos, esas, este, esta, estos, estas, aquel, aquella, aquellos i aquellas) poden funcionar com a adjectius i com a pronoms.

La Reial Acadèmia Espanyola, en l'Ortografía (des de 1959), indica que és potestatiu accentuar aquests pronoms en castellà i que és necessari fer-ho si hi ha risc d'ambigüitat. 
Tenint en compte que el risc d'ambigüitat és molt petit i que és molt difícil trobar alguna frase en la qual n'hi hagi, en els textos empresarials no s'han d'accentuar mai aquestes paraules.

Les formes neutres castellanes (eso, esto, aquello) mai no han de dur accent gràfic, ja que no poden confondre's: només funcionen com a pronoms.

El canvi més recent va ser el que va aparèixer per primera vegada en l'Ortografía de 1999, llibre redactat amb l'acord de totes les acadèmies: les formes verbals amb pronoms enclítics, que en les anteriors normes ortogràfiques del castellà mantenien l'accent del verb (déme, cayóse...), a partir de l'última edició de l'Ortografía de la Reial Acadèmia Espanyola s'accentuen d'acord amb les normes generals d'accentuació (deme, cayose...).

Fins aquí els principals problemes gràfics que es poden trobar en qualsevol document escrit de qualsevol empresa del món castellà, sigui als EUA, a l'Amèrica llatina o a Espanya.

Un altre fenomen lingüístic difícil d'eradicar és la tendència - especialment en les empreses dedicades a la tecnologia- a usar paraules castellanes com ingeniero o arquitecto, així, en masculí, tant si es refereixen a un home com a una dona.

Durant molts anys els femenins de les professions i dels càrrecs es van usar en castellà per fer referència a les dones dels homes que els exercien: la médica era la dona del metge, l'embajadora era la dona de l'ambaixador, la notaria era la dona del notari... Però aquests temps, afortunadament, ja són història. En el castellà modern hem de reflectir la realitat de l'època en la qual ens ha tocat viure: una època en la qual les dones ocupen càrrecs $\mathrm{i}$ desenvolupen professions que abans eren només masculines.

El 22 de març de 1995 es va aprovar una ordre del Ministeri d'Educació i Ciència per la qual els títols acadèmics oficials designats tradicionalment en masculí van passar a tenir la versió corresponent en femení. Amb aquesta ordre es van canviar oficialment 21 títols, entre els quals es trobaven els de doctora, ingeniera, técnica, licenciada, graduada, diplomada, arquitecta, maestra, profesora, médica, farmacéutica, enfermera, etc. Redactada amb la col laboració de la Reial Acadèmia Espanyola i l'Institut de la Dona, l'ordre establia que tots els títols, certificats o diplomes oficials referits a les professions i activitats múltiples havien de tenir en compte la condició masculina o femenina de qui els obtinguessin.

Tot i que en aquesta ordre es fa només esment als títols acadèmics, cal generalitzar l'ús del femení (sempre que no resulti forçat) a tots els noms d'oficis i càrrecs que tradicionalment eren ocupats només per homes: presidenta, senadora, diputada, etc.

Els noms de càrrecs o professions (que són noms comuns) acabats en castellà en $e$ o en $o$ canvien aquestes vocals per $a$ per formar el femení (camarero/camarera). No obstant això, alguns noms acabats en $e$ fan el femení amb la terminació -esa (alcalde/alcaldesa). Els noms acabats en consonant $d, l, n, r, s$ o $z$, afegeixen una a (asesor/asesora, concejal/concejala, juez/ jueza). També aquí es donen algunes excepcions, com abad/abadesa. En el cas dels noms de professions, ocupacions o altres acabats en -ente cal tenir en compte que en molts casos l'ús del femení no està generalitzat (gerente/gerenta, paciente/pacienta). Ara bé, són comuns els parells president/presidenta, cliente/clienta, asistente/asistenta... Caldrà, doncs, esperar que l'evolució en la societat i l'ús dels parlants determinin aquests canvis, però al que no podem esperar ja més és que les enginyeres siguin ingenieras, i les caps d'àrea siguin jefas de área.

Avui, però, si mirem aquesta carpeta allargada que usem per guardar les targetes de visita que ens van arribant a les mans, podrem comprovar que en la major part dels casos, quan és una dona la que hi apareix, el nom en castellà de l'ofici o del càrrec que desenvolupa continua en masculí, com si una biólogo sabés més i fos més prestigiosa que una bióloga.

Es tracta, ni més ni menys, que la dona deixi de ser invisible $i$ aparegui on ha d'aparèixer, sense caure en el vertigen del desdoblament a ultrança, tal com ja fan alguns polítics d'Espanya i tal com van fer els redactors de la Constitució de la República 
Socialista Bolivariana de Veneçuela, el 1999, de la qual serveix com exemple aquest fragment:

«Artículo 41. Sólo los venezolanos y venezolanas por nacimiento y sin otra nacionalidad, podrán ejercer los cargos de Presidente o Presidenta de la República, Vicepresidente Ejecutivo o Vicepresidenta Ejecutiva, Presidente o Presidenta y Vicepresidentes o Vicepresidentas de la Asamblea Nacional, magistrados o magistradas del Tribunal Supremo de Justicia, Presidente o Presidenta del Consejo Nacional Electoral, Procurador o Procuradora General de la República, Contralor o Contralora General de la República, Fiscal o Fiscala General de la República, Defensor o Defensora del Pueblo, Ministros o Ministras de los despachos relacionados con la seguridad de la Nación, finanzas, energía y minas, educación; Gobernadores o Gobernadoras y Alcaldes o Alcaldesas de los Estados y Municipios fronterizos y aquellos contemplados en la ley orgánica de la Fuerza Armada Nacional.

Para ejercer los cargos de diputados o diputadas a la Asamblea Nacional, Ministros o Ministras; Gobernadores o Gobernadoras y Alcaldes o Alcaldesas de Estados y Municipios no fronterizos, los venezolanos y venezolanas por naturalización deben tener domicilio con residencia ininterrumpida en Venezuela no menor de quince años y cumplir con los requisitos de aptitud previstos en la ley.»

Haurà llegit algun redactor de textos d'alguna empresa El dardo en la palabra de Fernando Lázaro Carreter? Em sorgeix aquest dubte quan, en revisar textos d'empreses en castellà topo constantment amb el mismo, la misma, los mismos i las mismas, recurs lleig, disgustant, poc elegant i molt avorridor, que Fernando va dur al ridícul en aquesta conversa apassionant entre una parella:

«-Juraría que me había echado las llaves al bolsillo de la chaqueta, pero no llevo las mismas en el mismo.

— ¿Te has mirado en el pantalón? Puedes llevarlas en los bolsillos del mismo.
-No, no llevo las mismas en el mismo... Al salir de casa, habré dejado las mismas sobre algún mueble de la misma, mientras sacaba el abrigo y me ponía el mismo.

-Tendrás que llamar al cerrajero para que abra la puerta.

- Sí, aquí tengo el teléfono del mismo. Nos cambió la cerradura de la misma hace poco, y conocerá la misma...»

I com avorreixen els verbs comodins que mai no falten en la literatura empresarial castellana! Són uns quants, però els més presents són tres, com els tres mosqueters, i avancen aferrissadament entre tot tipus de documents, tècnics, jurídics, comercials o publicitaris: realizar, iniciar i finalizar.

N'hi ha prou amb fixar-se una mica, o ser assessor lingüístic i revisor de textos, per topar-hi cada dos per tres. El més present en castellà és realizar, tot, absolutament tot es realiza, i res no se lleva a cabo, se ejecuta, se desarrolla, se imparte, se plasma, se fabrica, se elabora, se compone, se confecciona, se construye, se produce...

Els altres dos, iniciar i finalizar, esborren d'un cop de ploma uns altres molt més precisos per a cada context: comenzar, empezar, principiar, inangurar, abrir, incoar, entablar, emprender, aparecer, surgir, arrancar, salir, desatarse, desencadenarse, nacer... o terminar, acabar, concluir, consumar, rematar, extinguir, finiquitar, ultimar, prescribir, liquidar, cerrar, sobreseer, sellar, levantar, vencer...

Coneixen els responsables de la documentació de les empreses l'existència d'uns llibres anomenats manuals d'esti? I d'altres coneguts com a diccionaris de dubtes? Saben que hi ha molt bons recursos a Internet per resoldre dubtes en l'ús de la llengua $i$ per consultar quan apareixen obstacles en la redacció? Jo m'atreviria a dir que no, que ho ignoren i a més no consideren que sigui important, encara que aquest mal no afecta el cent per cent de les empreses; per sort algunes se'n salven, poques, i serveixen com a exemple per a les altres.

Si bé els llibres i manuals d'estil s'han circumscrit, des que van aparèixer, a un tipus d'empreses molt determinat —els mitjans de 
comunicació (diaris, televisions i ràdios)-, de mica en mica es publiquen llibres dedicats al llenguatge específic d'altres tipus de negocis o activitats, com les universitats, els despatxos d'advocats, els ajuntaments, etc.

El primer d'aquests llibres dedicat al llenguatge d'empresa en el qual vaig participar com a coautor es va editar el 2007 i és el Libro de estilo de Red Eléctrica de España. Amb aquesta publicació, els responsables de l'empresa pretenen assolir que els documents, tot el que allí s'hi escriu i s'hi imprimeix, estiguin redactats en un bon castellà. A més, per assolir aquest objectiu, van organitzar uns cursos durant el 2006 i el 2007, en els quals el professor Xosé Castro Roig i jo mateix vam explicar a tots els treballadors de Red Eléctrica de España les claus necessàries per aconseguir aquest castellà correcte.

Cursos semblants s'organitzen cada dia $\mathrm{amb}$ més freqüència en moltes empreses espanyoles (i suposo que en empreses hispanoamericanes i nord-americanes), i ja apareixen centres especialitzats en formació per a empreses.

A més, la Fundación del Español Urgente (Fundéu BBVA), el propòsit fundacional de la qual és assessorar els mitjans de comunicació d'Amèrica i d'Espanya per millorar la qualitat del castellà — de la qual sóc el coordinador general-, ofereix també serveis a empreses que estan interessades que les publicacions (informes, contractes, fullets, butlletins, memòries...) estiguin escrites en castellà correcte, $\mathrm{i}$ ja són unes quantes les que ens han contractat amb aquesta finalitat.

El nostre treball consisteix a revisar $\mathrm{i}$ corregir tota la documentació que ens envien, i si així ho volen posem a la seva disposició un certificat de qualitat idiomàtica sempre que es comprometin a atenir-se a les recomanacions que els fem. És habitual, a més, que els qui contracten els nostres serveis ens demanin també que impartim cursos als treballadors sobre el bon ús del castellà.

En tot aquest tema de l'assessorament lingüístic a les empreses hi ha una cosa que no es té encara gaire en compte i que em sembla interessant assenyalar per acabar aquest article: la globalització del castellà.

El primer que cal fer és llegir l'últim llibre del secretari general de l'Asociación de Academias de la Lengua Española, Humberto López Morales, titulat La globalización del léxico hispánico, i el segon és obrir bé les oïdes i els ulls per parar esment al que es diu i s'escriu en els documents de les empreses transnacionals que operen a banda $\mathrm{i}$ banda de l'Atlàntic.

El castellà no és la llengua d'un país, sinó de 21 -si comptem els EUA- i en cadascun es parla de manera diferent, $i$ fins $i$ tot dintre de cadascun hi ha diverses maneres, ja que no és el mateix la parla de Bogotá que la de Barranquilla o la de Medellín, i això que totes són ciutats colombianes. Hi ha, això sí, una norma culta estàndard, internacional, usada per la gent amb estudis, però cal estar alerta i vigilar els documents que van d'un país a un altre perquè no es colin localismes que dificultin la comprensió del text.

No és una tasca fàcil, ja que per al parlant d'un lloc el seu castellà és neutre i els altres són diferents, però tampoc no és una tasca impossible si s'està atent $\mathrm{i}$ es revisen els documents abans d'enviar-los.

En resum: en assessorar una empresa sobre l'ús del castellà i impartir cursos o tallers sobre aquesta matèria dirigits als treballadors de les empreses, cal tenir en compte molts aspectes del llenguatge: l'ortografia, l'ortotipografia, la morfologia, la sintaxi, el lèxic... I cal tenir molt present que el castellà és una llengua viva, per la qual cosa cal no tancar-li el pas a les innovacions. 